\title{
CORRESPONDENCE
}

Waiting lists for cardiac surgery

K K Nair, FRCS, and S R Dunn, FFARCS . . . 890

Medical care in inner cities

D C Morrell, FRCGP . . . . . . . . . . . . 890

Sexual pressures on children

G R Kinghorn, MRCP; Valerie Riches

Reverend J B Metcalfe, MB; Madeleine

Simms, MSC; M Jarmulowicz. . . . . . . . . 891

Hospital equipment "Which?"

P M Harms, MIEE . . . . . . . . . . . . 892

Comparison of the tine and Mantoux

tuberculin tests

A J Johnson, MRCP, and J A Lunn, MD . . . 892

Health Service planning and medical education

R Wilkinson, MRCP

Confidentiality of medical records

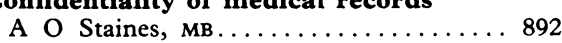

Postoperative morbidity and mortality after bleomycin treatment

I G Schraibman, FRCS; P L Goldiner, MD,

and G C Carlon, MD . . . . . . . . . . . . . . 892
Radiology work load

M D Rosewarne, FRCR; K Swinburne, DMRD

Joyce F Andrews, TDCR .......... 893

Beta-blockers in treatment of

hypertension

D M Harris, MD, and D A Richards, MD . . 894

Investigating stroke

F Mills, MRCP................. 894

Chlormethiazole addiction

M M Glatt, FRCPSYCH . . . . . . . . . . . 894

Breathing other people's smoke

R S F Schilling, FRCP, and A Bouhuys;

B J-L Sudan, MD; Betty Brody. . . . . . . . . 895

Uniform style for biomedical journals

R Carlisle, FRCP, and others . . . . . . . 895

Misdiagnosis of amoebiasis

A L Jeanes, FRCPATH............ 895

Melatonin as a marker for pineal tumours

S G Barber, MRCP. . . . . . . . . . . 896

Whooping cough

D Jenkinson, мв ............. 896
Arenaviruses in perspective

K M Pavri . . . . . . . . . . . . . . . . . . . . 896

Underdiagnosis of childhood asthma

A D Clift, MD, and B Jean Day ......... 896

HDL cholesterol and coronary artery occlusion

J J Barboriak, sCD . . . . . . . . . . . . . 897

Adverse reactions to intravenous

induction agents

H L Thornton, FFARCS...

Lord Mayor Treloar Hospital, Alton

M C Wilkinson, FRCs.............. 897

Negotiating rights for junior hospital doctors

T McFarlane, MRCog. . . . . . . . . . . . . . 897

Distribution of registrars

V M Demmery. . . . . . . . . . . . . . 898

General practice records

J T Hart, FRCGP; H W K Acheson, FRCGP . . 898

Related ancillary staff

H Gordon, мғсм............... 898

Priorities in planning

R H Hardy, DM.
Correspondents are urged to write briefly so that readers may be offered as wide a selection of letters as possible. So many are being received that the omission of some is inevitable. Letters must be signed personally by all their authors. As stated each week in "Instructions to authors" no letter will be acknowledged unless a stamped addressed envelope or an international reply coupon is enclosed.

\section{Waiting lists for cardiac surgery}

SIR,-Recently it has been revealed that there is a variation in the length of waiting lists for cardiac operations in England. This culminated in two patients going to private clinics in London for their operations.

At the cardiothoracic unit in Castle Hill Hospital, Cottingham, North Humberside, there is no waiting list for cardiac operations. The maintenance of expertise, facilities, and medical, nursing, and technical personnel is

\section{Medical care in inner cities}

SIR,-I have read with interest the opinions expressed in the discussion on medical care in inner cities (19 August, p 545) and the ensuing correspondence. Dr R Law (9 September, $p$ 767) condemns the medical schools of London for their lack of interest in this problem. My contribution to this correspondence is based on facts collected by the district administrator and myself in visits to the surgeries of $50 \%$ of the general practitioners in the St Thomas's District. From this survey and a study of the problems of other boroughs, it is possible to draw certain conclusions.

(1) The inner city problem in London varies from one borough to another. In Lambeth, for instance, patients have no problem in finding a general practitioner. This is in contrast to the serious problems experienced in Kensington, Chelsea, and Westminster, where list sizes tend to be low but many doctors are expensive. Is it time for us to have a national waiting list for this type of surgery? Within the NHS we could avoid some of the waitinglist mortality which occurs in some parts of the country.

K K NAIR S R DUNN

Department of Anaes hesia,

Hull Royal Infirmary,

engaged in private practice. Dr D Stephens (p 767) draws attention to this problem and suggests that if practice in Southwark was more profitable than in Harley Street the standard of care would be the best in the world. I know of no evidence that the standards of general practitioner care in Harley Street are superior to those in Southwark and would be intrigued to apply the criteria suggested by Dr John Fry (p 767) in both situations.

(2) The provision of suitable premises presents a serious problem in London and many are too small to make possible the development of the primary health care team. Most of the doctors we visited were not interested in health centres, some because they were afraid of increased expenses, some because they did not see the relevance to the primary health care team, and some because the recent behaviour of our political leaders in the Health Service made them anxious about their professional freedom. The best premises we visited were purpose-built by local authorities and rented by the doctors, but many doctors described difficulties in obtaining planning permission and space to develop their own premises.

(3) The question of recruitment to general practice in London is crucial. New vocationally trained doctors are unlikely to practise in London unless they are taken into an existing partnership. Death and retirement vacancies tend to go to doctors who have qualified abroad and spent several years as assistants in general practice in Britain. The experience in general practice which they have acquired in this way gives them a great advantage with selection committees.

(4) The greatest problem which we encountered in our visits was that of isolation. Nearly one-third of the doctors were singlehanded and had little contact with their colleagues in general practice, the specialists to whom they referred patients, their community nurses, or health visitors. Despite this, most of them were content with the services they provided, the premises in which they worked, and the facilities provided by the hospital. The fact that general practice in the last two decades has changed from a demandorientated service to one concerned with continuity of care and prevention was not always appreciated. This is not a problem which can be solved by legislation; it requires education.

It would be a great pity if the concept of primary, personal, and continuing care by independent contractors was rejected in the inner cities simply because the problems are difficult to solve. It is only in one or two boroughs that the mobility of the population precludes continuity of care. In most areas the mobility is confined to about $20 \%$ of the population while 60 to $80 \%$ remain stable. What is required is a careful analysis of the problems at district level, and in London this 